\title{
(6)
}

\section{LA BALANZA COMERCIAL AGROALIMENTARIA EN 2018}

En este artículo se analiza la evolución de los principales sectores y mercados agrarios durante el año 2018, así como los factores más importantes que determinan el comportamiento de nuestra balanza agroalimentaria. Se ha incluido el análisis sectorial de los productos de los veinticuatro primeros capítulos del arancel.

Palabras clave: importaciones, exportaciones, comercio exterior, agricultura, España, 2018. Clasificación JEL: Q10, Q17.

\section{Introducción}

En este artículo se estudia la evolución de la balanza comercial agroalimentaria en el año 2018.

En el epígrafe 2 se describe la evolución general del comercio exterior agroalimentario, que ha observado una tendencia positiva en los últimos años. Se presenta, además, la evolución de las exportaciones e importaciones agroalimentarias desagregadas por los 24 capítulos del arancel que corresponden a este ámbito.

El epígrafe 3 presenta un detalle sectorial de los datos de comercio exterior. Por limitaciones de espacio no se ha podido incluir el análisis sectorial de todos los productos de los 24 primeros capítulos del arancel.

\footnotetext{
* Ministerio de Industria, Comercio y Turismo. Versión de octubre de 2019.

DOI: https:/doi.org/10.32796/bice.2019.3117.6924
}

En el epígrafe 4 se analiza la distribución geográfica del comercio exterior agroalimentario, según los países o áreas geográficas de destino de las exportaciones y origen de las importaciones. Además, se describen los hechos más relevantes que han afectado al comercio exterior de productos agroalimentarios durante 2018.

\section{Evolución general}

De acuerdo con los datos de comercio exterior (Cuadro 1), la balanza comercial agroalimentaria, que comprende los 24 primeros capítulos del arancel, ha registrado en 2018 un superávit de más de 11.376 millones de euros y una ratio de cobertura de 131,3\%. El superávit ha sido inferior al de 2017 y superior al de 2016; el de 2017 fue el mayor valor registrado desde el año 2003, que en los últimos dieciocho años ha contado con un saldo positivo en la $\triangleright$ 
CUADRO 1

EVOLUCIÓN DEL COMERCIO EXTERIOR ESPAÑOL DE PRODUCTOS AGROALIMENTARIOS

(Miles de euros)

\begin{tabular}{|l|l|l|l|l|c|c|}
\hline Año & Exportación & Importación & Saldo & \% Cobertura & \multicolumn{2}{|c|}{ \% sobre total mercancías } \\
\hline 2004 & 21.953 .570 & 20.391 .814 & 1.561 .756 & 107,7 & 14,9 & 9,8 \\
2005 & 22.569 .690 & 22.088 .969 & 480.720 & 102,2 & 14,6 & 9,5 \\
2006 & 23.883 .309 & 22.697 .096 & 1.186 .213 & 105,2 & 14,0 & 8,6 \\
2007 & 25.861 .548 & 25.530 .201 & 331.346 & 101,3 & 14,0 & 9,0 \\
2008 & 27.811 .138 & 26.912 .110 & 899.028 & 103,3 & 14,7 & 9,5 \\
2009 & 26.520 .841 & 23.888 .612 & 2.632 .230 & 111,0 & 16,6 & 11,6 \\
2010 & 29.100 .551 & 25.753 .433 & 3.347 .118 & 113,0 & 15,6 & 10,7 \\
2011 & 32.168 .087 & 28.357 .730 & 3.810 .356 & 113,4 & 14,9 & 10,8 \\
2012 & 35.628 .140 & 29.225 .268 & 6.402 .872 & 121,9 & 15,8 & 11,3 \\
2013 & 37.195 .596 & 28.814 .872 & 8.380 .724 & 129,1 & 15,8 & 11,4 \\
2014 & 38.687 .873 & 29.636 .446 & 9.051 .427 & 130,5 & 16,1 & 11,2 \\
2015 & 42.057 .749 & 32.293 .044 & 9.764 .705 & 130,2 & 16,8 & 11,8 \\
2016 & 44.613 .193 & 33.422 .076 & 11.191 .117 & 133,5 & 17,4 & 12,2 \\
2017 & 47.528 .535 & 36.003 .519 & 11.525 .016 & 132,0 & 17,2 & 11,9 \\
2018 & 47.744 .816 & 36.368 .508 & 11.376 .308 & 131,3 & 16,8 & 11,4 \\
\hline Los datos correspondientes a 2018 son provisionales. & & & & \\
Fuente: elaboración propia con datos del Departamento de Aduanas e Impuestos Especiales. &
\end{tabular}

balanza comercial. La crisis económica no ha impedido que se mantenga la voluntad exportadora de nuestro sector agroalimentario, incluso la ha aumentado. En el Gráfico 1 también se puede observar esta evolución positiva, con un aumento de la divergencia entre las exportaciones y las importaciones a partir de 2007, que da lugar a un aumento progresivo del saldo.

Las exportaciones agroalimentarias (Cuadro 2) supusieron 47.745 millones de euros y 34.984.198 toneladas en 2018. En relación con la exportación total de bienes (285.024 millones de euros), las exportaciones agroalimentarias significaron el $16,8 \%$, por debajo de la participación del año 2017 (17,2\%).

Con respecto al año 2017, se ha producido un aumento en valor de un 0,5\% (216 millones de euros), y en volumen, del 2,7\% (716.253 toneladas).

En volumen, hay nueve capítulos (uno más que en los dos años anteriores) que superan el millón de toneladas de exportación, y suponen el $83,2 \%$ del total exportado: 8 (frutas y frutos $\sin$ conservar), 7 (legumbres y hortalizas sin conservar), 22 (bebidas), 20 (conservas y zumos vegetales), 2 (carne y despojos comestibles), 15 (grasas y aceites animales o vegetales), 23 (residuos de la industria alimentaria), 12 (semillas oleaginosas y plantas industriales) y 10 (cereales).

En cuanto al valor, doce capítulos (igual que en 2017 y uno más que en 2016) han superado los mil millones de euros, suponiendo el $88,6 \%$ del total: capítulos 8 (frutas y frutos sin conservar), 7 (legumbres y hortalizas sin conservar), 2 (carne y despojos comestibles), 22 (bebidas), 15 (grasas y aceites animales o vegetales), 3 (pescados, crustáceos, moluscos), 20 (conservas vegetales y zumos), 19 (productos a base de cereales), 16 (conservas de carne o de pescado), 21 (preparaciones alimenticias diversas), 4 (leche y productos lácteos, y huevos) y 23 (residuos de la industria alimentaria). 


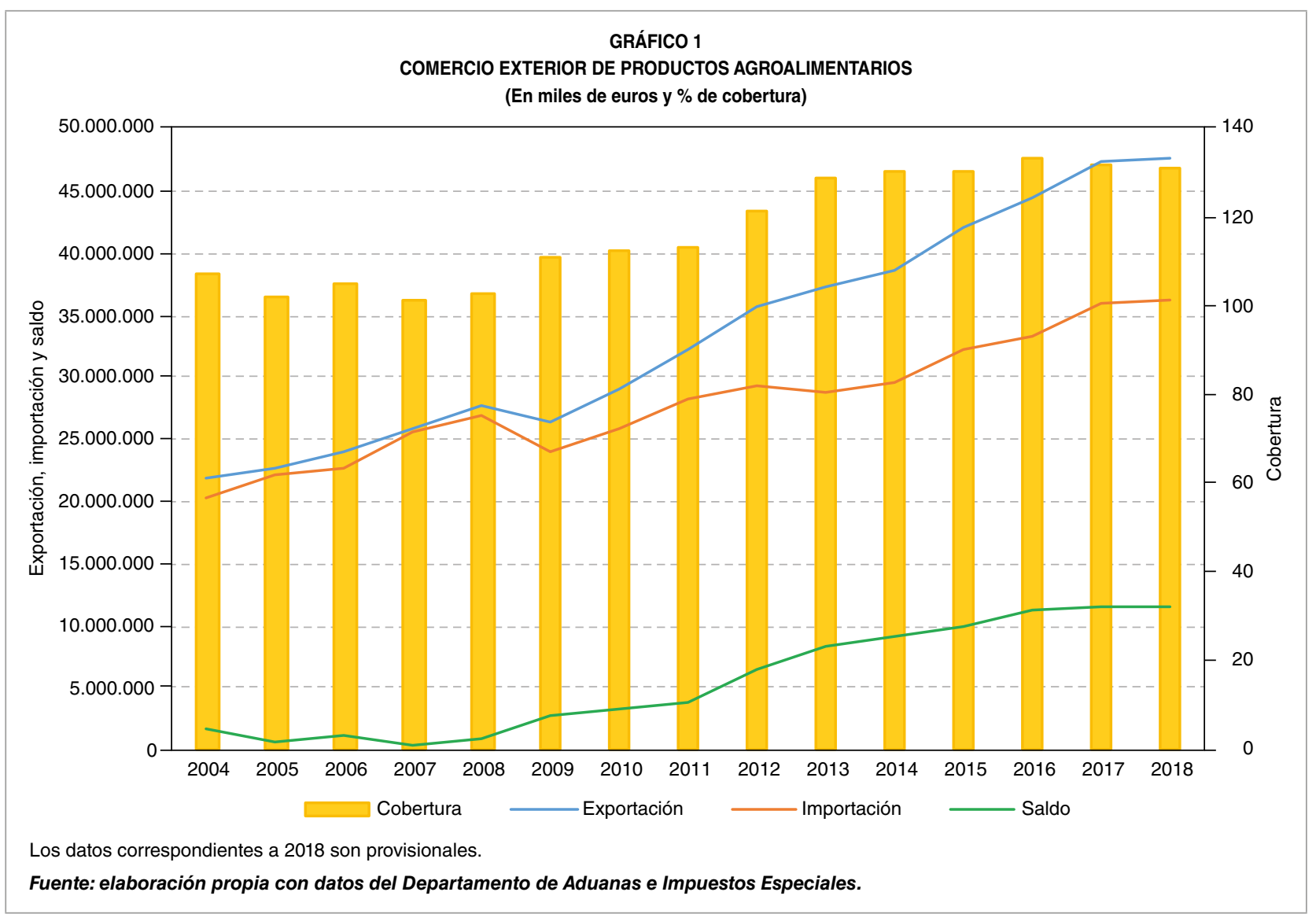

La subida del volumen de las exportaciones se ha debido principalmente a los capítulos 12 (semillas oleaginosas y plantas industriales), 10 (cereales) 7 (legumbres y hortalizas sin conservar), 23 (residuos de la industria alimentaria) y 15 (grasas y aceites animales o vegetales), todos ellos con aumentos superiores a 100.000 toneladas. Proporcionalmente destacan en volumen los incrementos de los capítulos 14 (materias trenzables), 10 (cereales), 12 (semillas oleaginosas y plantas industriales), avituallamiento y 2 (tabaco), cada uno con un aumento superior al $10 \%$. Por otro lado, han disminuido las exportaciones en más de un $10 \%$ el capítulo 5 (otros productos de origen animal), y en menos del $10 \%$ los capítulos 8 (frutas y frutos sin conservar), 22 (bebidas), 21 (preparaciones alimenticias diversas), 9 (café, té, yerba mate y especias) y 20 (conservas vegetales y zumos). El tonelaje de los demás capítulos 1 a 24 del arancel ha aumentado.

Respecto del valor, destaca el incremento de las exportaciones en los capítulos 22 (bebidas) y 3 (pescados, crustáceos, moluscos), ambos con aumentos superiores a cien millones de euros. También se observa aumento de la exportación en los demás capítulos, excepto el 15 (grasas y aceites animales o vegetales), 4 (leche, productos lácteos y huevos), 9 (café, té, yerba mate y especias), 2 (carnes y despojos comestibles), 5 (otros productos de origen animal) y 24 (tabaco y sus sucedáneos). Proporcionalmente, los productos con mayor aumento (superior al $10 \%$ ) en las exportaciones han sido los de los capítulos 14 (materias trenzables), 13 (jugos y extractos vegetales), 6 (plantas y flores), 12 (semillas oleaginosas y plantas industriales) y 10 (cereales). Han registrado $D$ 


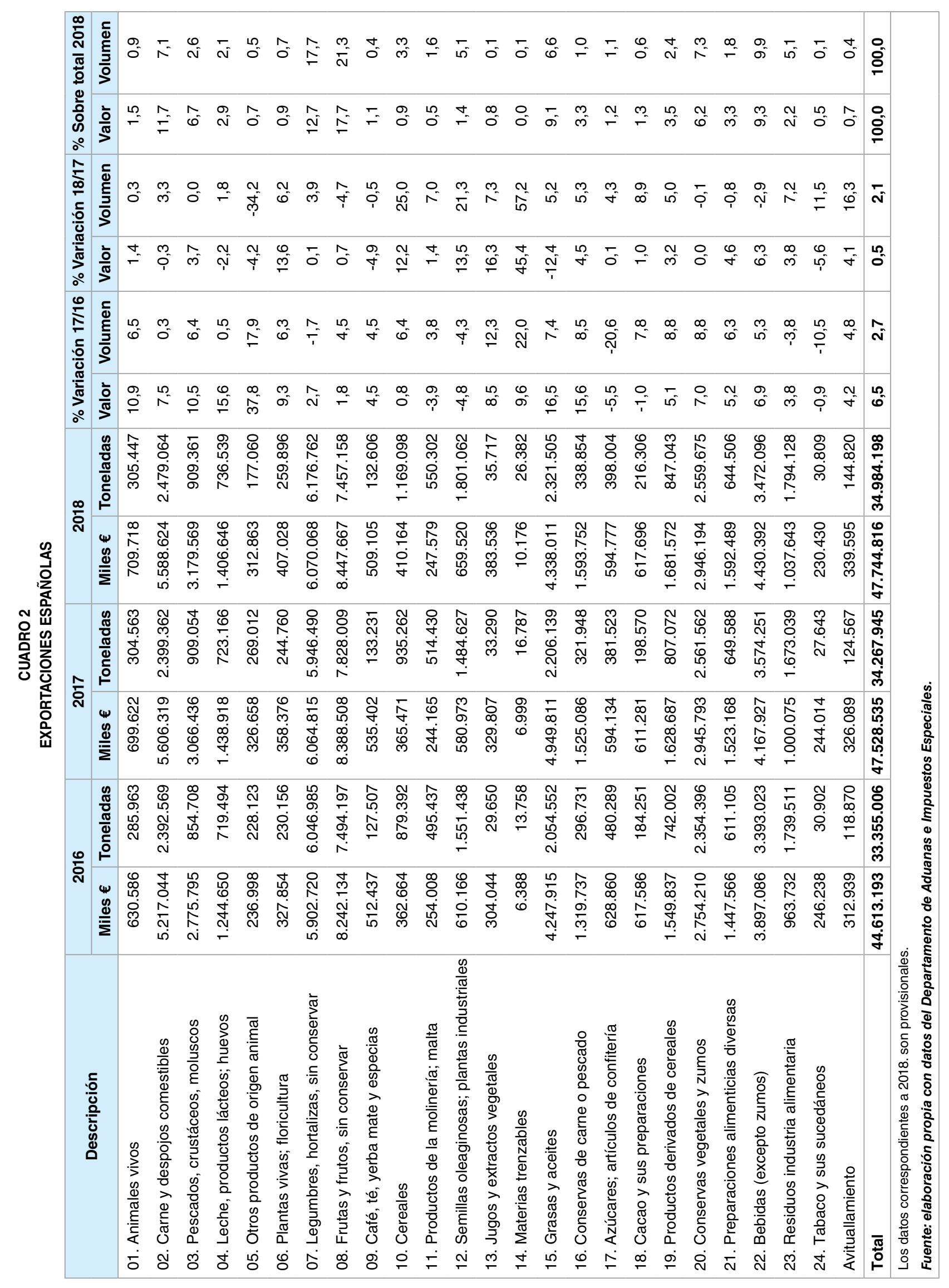


descensos seis capítulos: el 15 (grasas y aceites animales o vegetales), el 24 (tabaco y sus sucedáneos), el 9 (café, té, yerba mate y especias), el 5 (otros productos de origen animal), el 4 (leche y productos lácteos y huevos) y el 2 (carne y despojos comestibles).

Las importaciones agroalimentarias (Cuadro 3) supusieron 36.369 millones de euros y 43.933.093 toneladas. En relación con la importación total española de bienes (318.864 millones de euros), el sector agroalimentario ha supuesto el $11,4 \%$ del valor total importado, muy similar $(0,5 \%$ inferior) al porcentaje de 2017 (11,9\%).

Con respecto al año anterior, y en términos de valor, en 2018 se ha producido un aumento del $1 \%$ de las importaciones agroalimentarias (365 millones de euros), debido fundamentalmente a los capítulos 10 (cereales), 8 (frutas y frutos sin conservar) y 7 (legumbres y hortalizas sin conservar), cada uno con un incremento superior a cien millones de euros. En términos porcentuales, los mayores aumentos se han producido en los capítulos 5 (otros productos de origen animal) y 10 (cereales), ambos con un incremento superior al $10 \%$. Ha habido una reducción de más de cien millones de euros en las importaciones de los capítulos 15 (grasas y aceites animales o vegetales), 9 (café, té, yerba mate y especias) y 17 (azúcares y productos de confitería). Otros productos con disminución de las importaciones con respecto a 2017 han sido, además del avituallamiento, los de los capítulos 18 (cacao y sus preparaciones), 2 (carne y despojos comestibles), 12 (semillas oleaginosas y plantas industriales), 11 (productos de la molinería y malta), 14 (materias trenzables) y 20 (conservas y zumos vegetales).

En cuanto al volumen, se ha producido una subida del 3,5\%. Destacan los capítulos 10 (cereales), 7 (legumbres y hortalizas sin conservar) y 8 (frutas y frutos sin conservar), cada uno con un incremento superior a 100.000 toneladas. En términos porcentuales, los mayores aumentos han tenido lugar en los capítulos 7 (legumbres y hortalizas sin conservar), 5 (otros productos de origen animal), 19 (productos derivados de cereales), 21 (preparaciones alimenticias diversas) y 14 (materias trenzables), con variaciones superiores al $10 \%$. Con disminuciones superiores a 100.000 toneladas se encuentran los capítulos 23 (residuos de la industria alimentaria), 19 (productos derivados de cereales), 11 (productos de la molinería y malta) y 15 (grasas y aceites animales o vegetales). Otros nueve capítulos han visto reducir sus importaciones en volumen en el año 2018.

El esquema de nuestras importaciones es similar al de años anteriores. En volumen hay nueve capítulos que superan el millón de toneladas, igual que en 2017 y 2016 . Estos son, por orden de importancia: capítulos 10 (cereales), 23 (residuos de la industria alimentaria), 12 (semillas oleaginosas y plantas industriales), 15 (grasas y aceites animales o vegetales), 7 (legumbres y hortalizas sin conservar), 8 (frutas y frutos sin conservar), 17 (azúcares, artículos de confitería), 3 (pescados, crustáceos y moluscos) y 22 (bebidas). Todos ellos suponen el $87,5 \%$ del total de las importaciones. Como se ha indicado, el principal capítulo es el de cereales, del que se han importado 17 millones de toneladas ( $39 \%$ del total).

En cuanto al valor, hay dieciséis capítulos que han superado los mil millones de euros, uno menos que en 2017 y 2016. El más relevante es el capítulo 3 (pescados, crustáceos y moluscos), del que se han importado $6.169 \mathrm{mi}-$ llones de euros y representa el $17 \%$ del total.

Por orden de importancia se trata de los capítulos 3 (pescados, crustáceos y moluscos), $\triangleright$ 


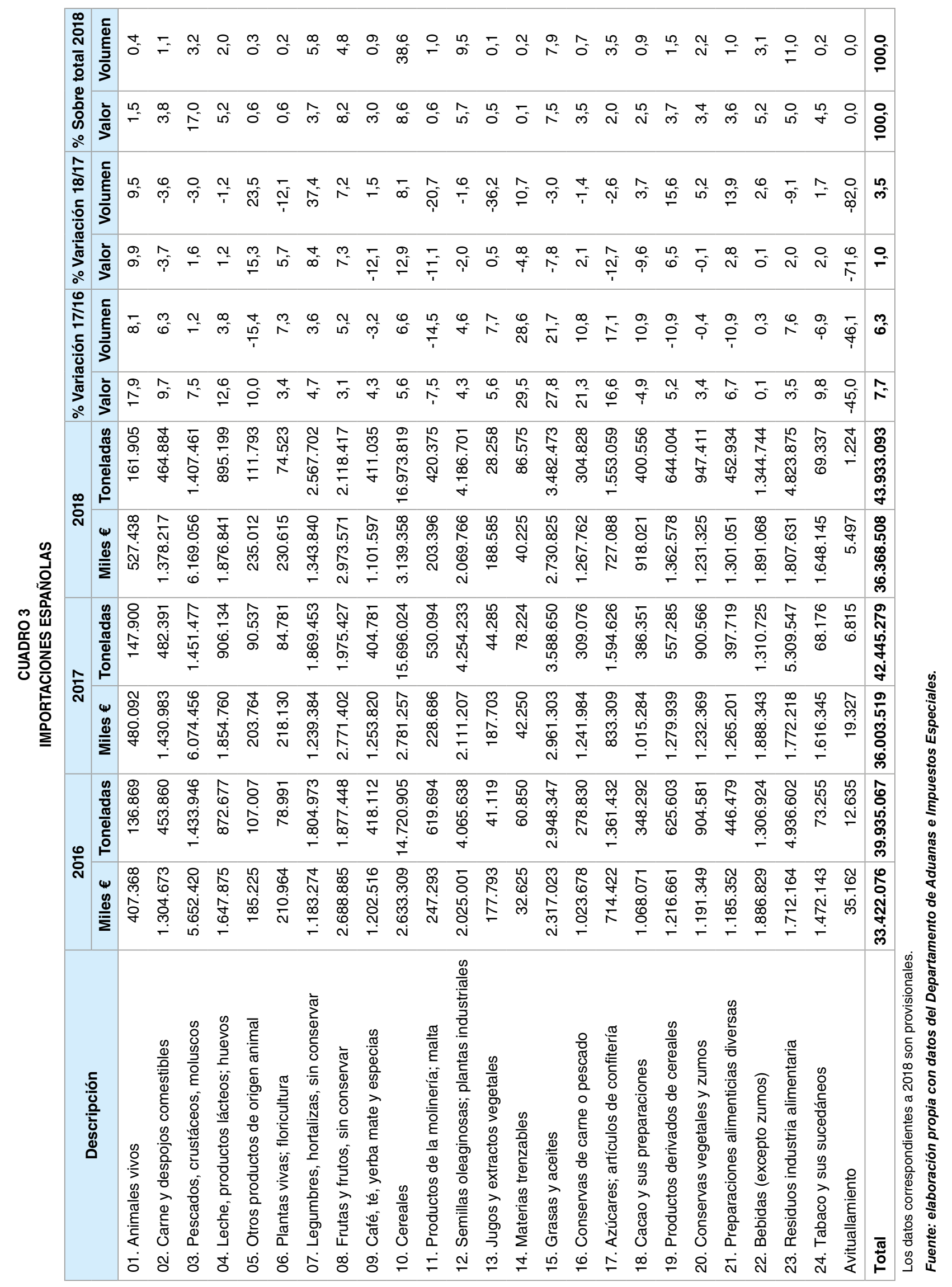


10 (cereales), 8 (frutas y frutos sin conservar), 15 (grasas y aceites animal o vegetales), 12 (semillas oleaginosas y plantas industriales), 22 (bebidas), 4 (leche, productos lácteos y huevos), 23 (residuos de la industria alimentaria), 24 (tabaco y sus sucedáneos), 2 (carne y despojos comestibles), 19 (productos derivados de cereales), 7 (hortalizas y legumbres), 21 (preparaciones alimenticias diversas), 16 (conservas de carne o de pescado), 20 (conservas y zumos vegetales) y 9 (café, té, yerba mate y especias). Todos ellos suponen el $91,5 \%$ del total.

\section{Análisis sectorial del comercio exterior agroalimentario}

El análisis sectorial se presenta resumido en este artículo. La balanza comercial con el análisis sectorial completo se encuentra en http://www.comercio.gob.es/es-ES/comercio-exterior/informacion-sectorial/agroalimentarios/estadisticas/Paginas/estadisticas.aspx

El Cuadro 4 permite tener una visión de conjunto del comercio exterior por sectores, que se desarrolla en la versión completa de la balanza agroalimentaria.

CUADRO 4

BALANZA COMERCIAL AGROALIMENTARIA POR SECTORES

(Miles de euros)

\begin{tabular}{|c|c|c|c|c|c|c|c|c|}
\hline \multirow[t]{2}{*}{ Descripción } & \multicolumn{3}{|c|}{2017} & \multicolumn{3}{|c|}{2018} & \multicolumn{2}{|c|}{$\begin{array}{c}\text { \% Variación } \\
2018 / 2017\end{array}$} \\
\hline & Exportación & Importación & Saldo & Exportación & Importación & Saldo & Export. & Import. \\
\hline Cárnicos & 7.076 .188 & 2.308 .487 & 4.767.701 & 7.084 .741 & 2.287 .401 & 4.797 .340 & 0,1 & $-0,9$ \\
\hline Bovino & 958.881 & 1.014 .449 & -55.568 & 1.053 .604 & 1.034 .741 & 18.863 & 9,9 & 2,0 \\
\hline Ovino-caprino & 316.422 & 71.933 & 244.489 & 319.586 & 73.582 & 246.004 & 1,0 & 2,3 \\
\hline Porcino & 5.064 .088 & 520.116 & 4.543 .972 & 4.914 .784 & 475.986 & 4.438 .798 & $-2,9$ & $-8,5$ \\
\hline Aves y huevos & 606.893 & 622.759 & -15.866 & 661.254 & 625.883 & 35.371 & 9,0 & 0,5 \\
\hline Otros animales & 129.904 & 79.230 & 50.674 & 135.513 & 77.209 & 58.304 & 4,3 & $-2,6$ \\
\hline Lácteos & 1.148 .731 & 1.693 .019 & -544.288 & 1.117 .215 & 1.703 .478 & -586.263 & $-2,7$ & 0,6 \\
\hline Pesca & 3.989 .190 & 6.995 .865 & -3.006 .675 & 4.167.321 & 7.156 .054 & -2.988 .733 & 4,5 & 2,3 \\
\hline Cereales y productos de molinería & 622.340 & 3.009 .412 & -2.387 .072 & 657.743 & 3.342 .755 & -2.685 .012 & 5,7 & 11,1 \\
\hline Residuos ind. alimentaria y piensos & 990.726 & 1.745 .760 & -755.034 & 1.037 .643 & 1.807 .631 & -769.988 & 4,7 & 3,5 \\
\hline Flores y plantas & 358.376 & 218.130 & 140.246 & 407.028 & 230.615 & 176.413 & 13,6 & 5,7 \\
\hline Hortalizas y legumbres & 6.031 .967 & 1.222 .886 & 4.809 .081 & 6.029 .287 & 1.323 .178 & 4.706 .109 & 0,0 & 8,2 \\
\hline Frutas & 8.388 .508 & 2.771 .402 & 5.617 .106 & 8.447 .667 & 2.973 .571 & 5.474 .096 & 0,7 & 7,3 \\
\hline Conservas vegetales & 2.753 .542 & 1.227 .564 & 1.525 .978 & 2.734 .493 & 1.219 .577 & 1.514 .916 & $-0,7$ & $-0,7$ \\
\hline Vinos, bebidas y vinagre & 4.214 .738 & 1.714 .765 & 2.499 .973 & 4.471 .215 & 1.728 .625 & 2.742 .590 & 6,1 & 0,8 \\
\hline Tabaco & 244.014 & 1.616 .345 & -1.372 .331 & 230.430 & 1.648 .145 & -1.417 .714 & $-5,6$ & 2,0 \\
\hline Grasas y aceites & 4.949 .811 & 2.961 .303 & 1.988 .508 & 4.338.011 & 2.730 .825 & 1.607 .186 & $-12,4$ & $-7,8$ \\
\hline Semill. oleagi., mandioca y forraje & 612.198 & 2.122 .961 & -1.510 .763 & 700.301 & 2.090 .428 & -1.390 .127 & 14,4 & $-1,5$ \\
\hline Café, té, cacao y azúcar & 949.724 & 2.243 .604 & -1.293 .880 & 944.116 & 1.946 .793 & -1.002 .677 & $-0,6$ & $-13,2$ \\
\hline Industrias agroalimentarias & 4.442 .512 & 3.770 .852 & 671.660 & 4.582 .113 & 3.813 .584 & 768.529 & 3,1 & 1,1 \\
\hline Otros productos & 755.970 & 2.768 .236 & -5.021 .678 & 795.492 & 365.848 & 429.644 & 5,2 & $-86,8$ \\
\hline Total & 47.528 .535 & 36.003 .519 & 11.525 .016 & 47.744 .816 & 36.368 .508 & 11.376 .308 & 0,5 & 1,0 \\
\hline
\end{tabular}




\section{Distribución geográfica del comercio exterior agroalimentario}

\subsection{Exportaciones por destino}

Los principales destinatarios de las exportaciones españolas son los demás países de la Unión Europea (UE). En el Cuadro 5 se puede observar que las exportaciones a la UE prácticamente no han variado en valor y en volumen han aumentado un $0,7 \%$, representando el $76,6 \%$ de nuestras exportaciones totales en volumen $(77,6 \%$ en 2017$)$ y del $73 \%$ en valor (73,3\% en 2017).

Considerados de manera individual, nuestros principales mercados en la UE son: Francia ( $16,2 \%$ en valor y $18,2 \%$ en volumen), Alemania ( $11,7 \%$ en valor y $12,9 \%$ en volumen), Italia ( $10,2 \%$ en valor y $8,2 \%$ en volumen), Portugal ( $9,3 \%$ en valor y $11,3 \%$ en volumen), y Reino Unido ( $8,3 \%$ en valor y $8 \%$ en volumen). Estos cinco países suponen el $58,7 \%$ de la exportación española en volumen y el 55,6\% en valor.

Fuera de la Unión Europea superan la cuota del $1 \%$ del volumen China (2,5\%), Emiratos Árabes Unidos (1,9\%), EE UU $(1,8 \%)$ y Marruecos $(1,3 \%)$. En valor superan el $1 \%$ de las exportaciones totales EE UU (4\%), China $(2,3 \%)$, Japón (1,9\%), Suiza (1,2\%), Corea del Sur $(1 \%)$ y Marruecos ( $1 \%)$.

Por bloques de países, son mercados relevantes los que forman parte del Acuerdo de Libre Comercio de América del Norte (NAFTA) y los países euromediterráneos. Las exportaciones españolas a NAFTA suponen el 2,7\% del volumen y el 5,5\% del valor total, y han aumentado con respecto a 2017 un 1,3\% en volumen y un $1,5 \%$ en valor. Tres cuartas partes del valor de estas exportaciones tienen como destino EE UU.

Nuestras exportaciones a los países euromediterráneos representan el $4,2 \%$ en volumen y el $3 \%$ en valor, y han aumentado un $29,4 \%$ en volumen y un $8,6 \%$ en valor.

\subsection{Importaciones por origen}

Los principales proveedores de productos agroalimentarios (Cuadro 6) son también los demás países de la UE. En términos porcentuales sobre el total de 2018, representan en volumen el $43,4 \%$ (49,3\% en 2017$)$ y en valor el $53,1 \%(54,1 \%$ en 2017$)$. Al comparar con las importaciones de 2017, y en términos porcentuales, disminuyen un $8,9 \%$ en volumen y un $0,7 \%$ en valor.

Los principales proveedores europeos en términos de volumen son: Francia (más de 7 millones de toneladas), Portugal, Rumania, Alemania (los tres con más de 1,5 millones de toneladas), Países Bajos y Bulgaria (estos dos con más de un millón de toneladas). En términos de valor, los principales proveedores son: Francia, Alemania, Países Bajos, Portugal, Italia y Reino Unido, todos ellos con importaciones superiores a mil millones de euros, y suponen el $41,2 \%$ del valor total importado por España. Fuera de la UE, igualan o superan la cuota del $1 \%$ del volumen Brasil (12,5\%), Ucrania (11,1\%), Estados Unidos (8,7\%), Argentina (4,6\%), Indonesia (2,9\%), Rusia (2\%), Marruecos $(1,4 \%)$, Canadá $(1,3 \%)$ y China (1,1\%).

Por lo que respecta al valor, cinco países superan el $5 \%$, uno más que el año pasado: Francia (13,5\%), Alemania (8,2\%), Países Bajos $(6,4 \%)$, Portugal $(5,7 \%)$ y EE UU $(5,1 \%)$. Fuera de la UE, además de EE UU superan el $1 \%$ Brasil (4,6\%), Marruecos (4,2\%), Argentina $(3,2 \%)$, Ucrania $(2,8 \%)$, China $(2,8 \%)$, Indonesia $(2,1 \%)$, Perú (1,8\%), Ecuador (1,5\%) y Chile $(1,1 \%)$. 
El siguiente grupo de países, por orden de importancia, es el Mercado Común del Sur (Mercosur). Al igual que en 2017, Mercosur mantiene la segunda posición entre los principales proveedores. En términos porcentuales sobre el total de 2017, Mercosur representa el $17,4 \%$ en volumen ( $19 \%$ en 2017 ) y el $8,1 \%$ en valor $(8,8 \%$ en 2017$)$. Las variaciones porcentuales respecto al año anterior indican un descenso en valor y en volumen $(6,6 \%$ y $4,9 \%$, respectivamente). Brasil y Argentina continúan siendo los principales proveedores tanto en volumen (5,5 millones y 2 millones de toneladas, respectivamente) como en valor (1.678 millones de euros Brasil y 1.170 millones Argentina).

El tercer grupo de países proveedores es NAFTA, con el $10,4 \%$ del volumen y el $6,3 \%$ del valor total importado. Con respecto a 2017, las importaciones han aumentado intensamente en volumen $(93,7 \%)$ y también sensiblemente en valor $(21,4 \%)$. Igual que en el caso de las exportaciones, alrededor de las tres cuartas partes $(80 \%)$ vienen de Estados Unidos.

También tienen relevancia las importaciones de los países euromediterráneos $(2,2 \%$ del volumen y $5,9 \%$ del valor) y las de la Asociación de Naciones del Sudeste Asiático (ASEAN), con un $4,5 \%$ del volumen y un $4,3 \%$ del valor. Las importaciones de los países Euromed han aumentado considerablemente ( $14,4 \%$ en volumen y $16,6 \%$ en valor), mientras que las de ASEAN han disminuido, un $8,4 \%$ en volumen y un $16,5 \%$ en valor.

Los hechos más relevantes relacionados con el comercio exterior de productos agroalimentarios en 2018 son los siguientes:

- A finales de 2017 y principios de 2018 EE UU impuso aranceles antisubvención y antidumping, respectivamente, a las importaciones de aceitunas negras españolas (ripe olives), que sumaban entre un $17 \%$ y un $26 \%$. A finales de julio de 2018 estas medidas pasaron a ser definitivas, con un $34,75 \%$. Esta medida ha provocado la reducción de las exportaciones de estas aceitunas a EE UU, que antes de la imposición representaba cerca de la cuarta parte de las exportaciones españolas de aceitunas.

- Argelia continúa con su política restrictiva a las importaciones de terceros países. En enero de 2018 anunció la suspensión de las importaciones de productos agroalimentarios de distintos sectores, entre otros, cárnicos, frutas y hortalizas, productos de molinería, productos de confitería, chocolate, pastas alimenticias, productos a base de cereales, conservas vegetales, zumos, salsas y sopas. A otros productos se les aumentó el derecho de importación (semillas oleaginosas, conservas vegetales, agua envasada, cerveza).

- En enero de 2018 las autoridades de Arabia Saudí comunicaron la prohibición de importar vacas españolas por motivo de la encefalopatía espongiforme bovina.

- El 1 de mayo de 2018 entró en vigor el Acuerdo entre la Unión Europea e Islandia sobre preferencias comerciales adicionales en el sector de los productos agrarios, que aumenta las preferencias ya existentes entre las partes del acuerdo, con base en lo dispuesto en el artículo 19 del Acuerdo sobre el Espacio Económico Europeo.

- El 14 de mayo de 2018 la Comisión Europea modificaba la lista de establecimientos autorizados de Brasil como consecuencia de las deficiencias $\square$ 


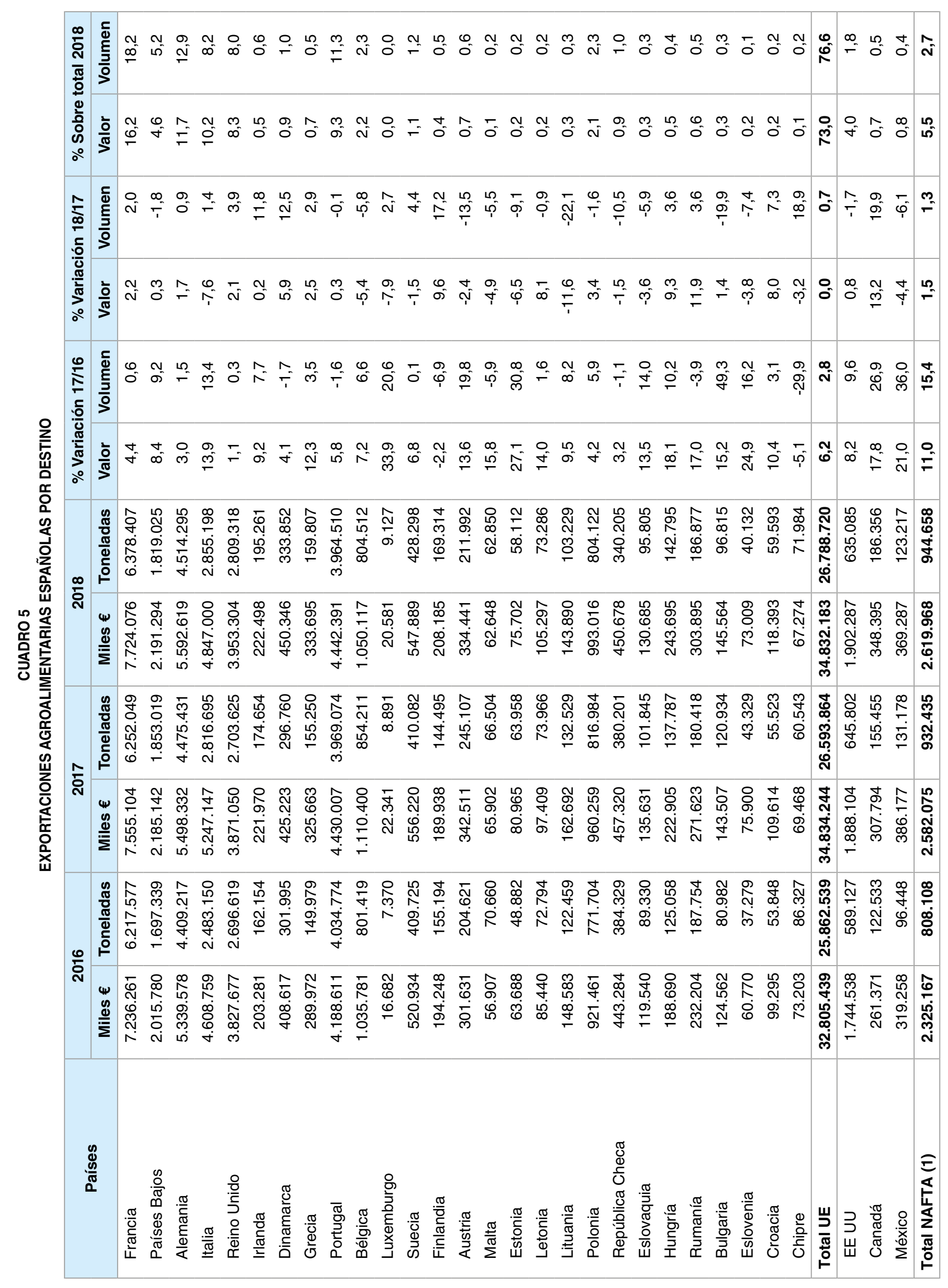




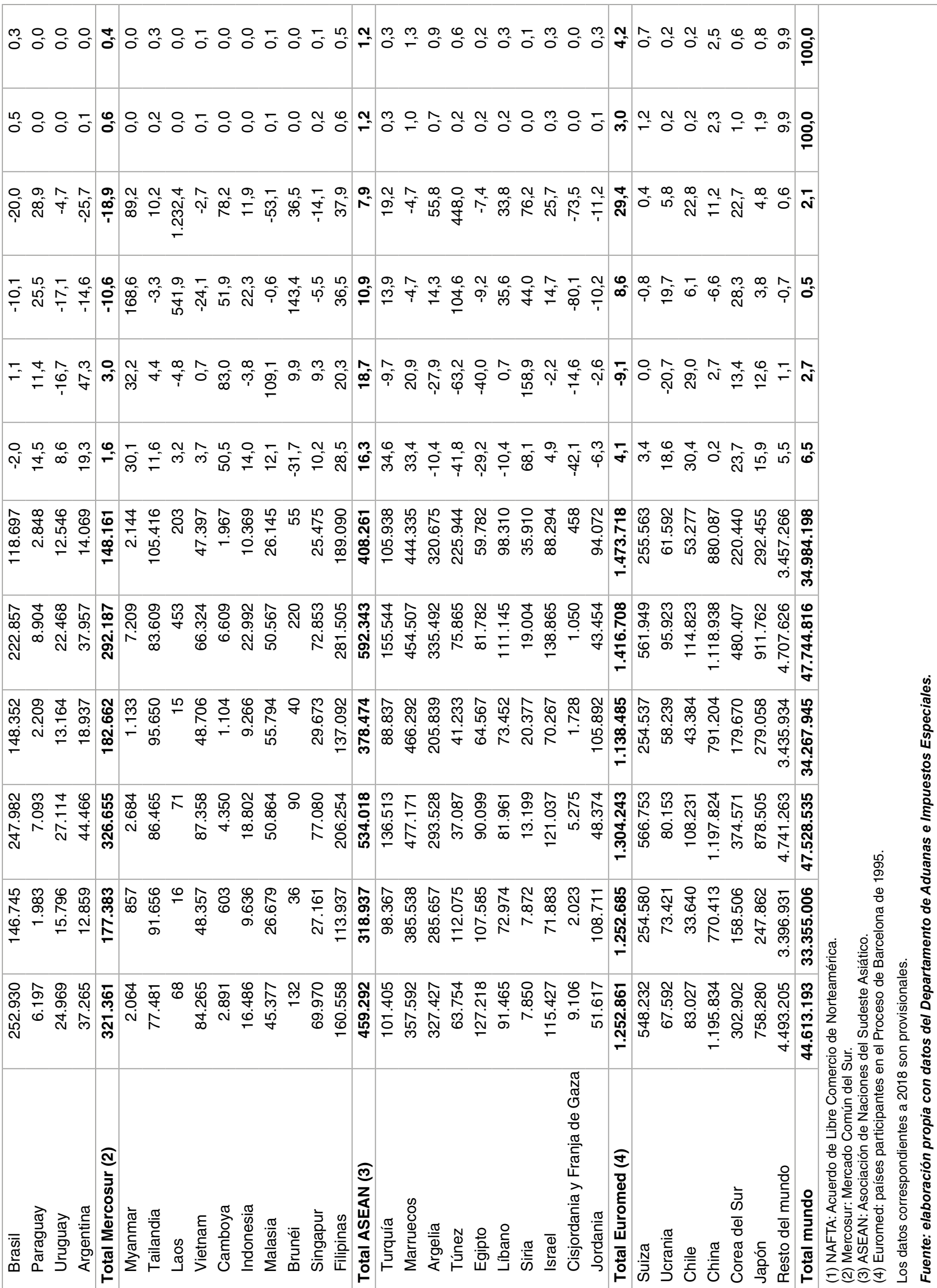




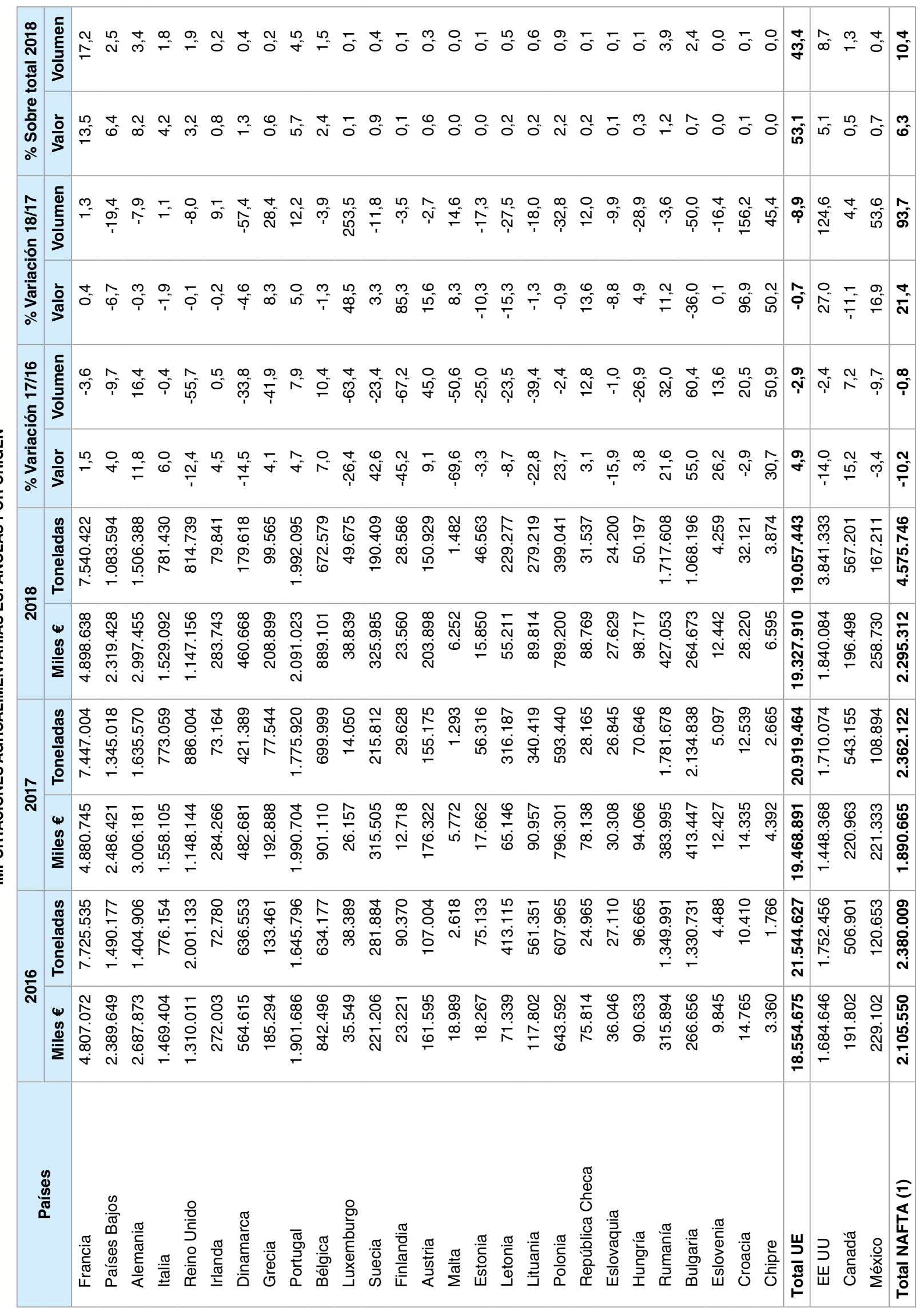




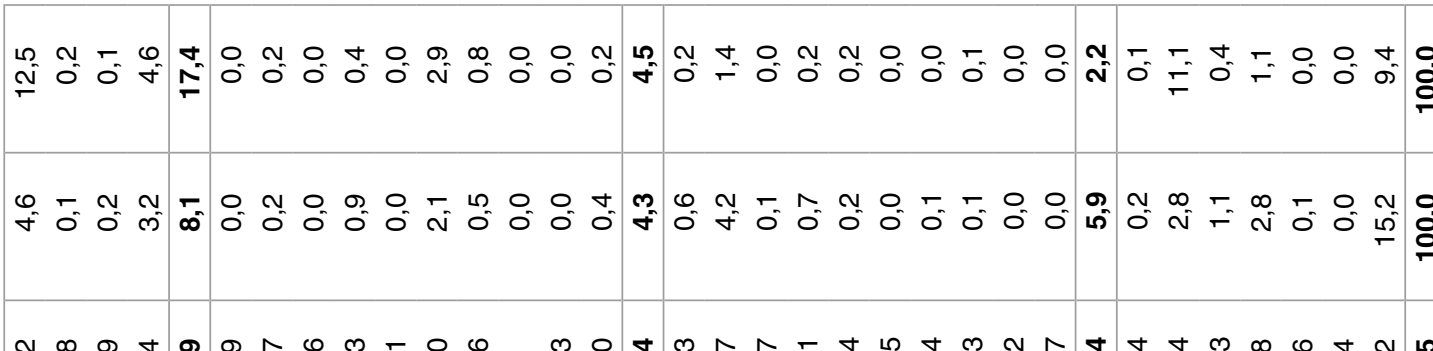

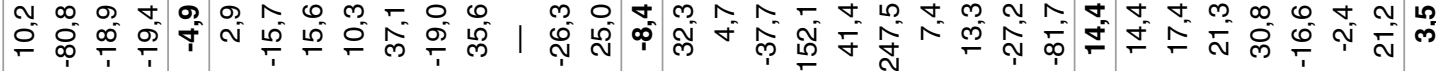

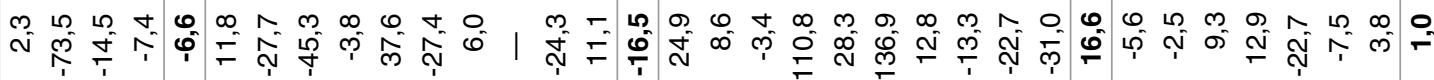

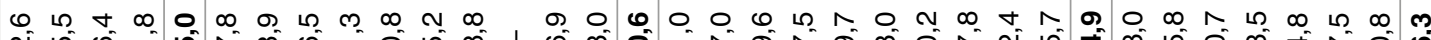
๙

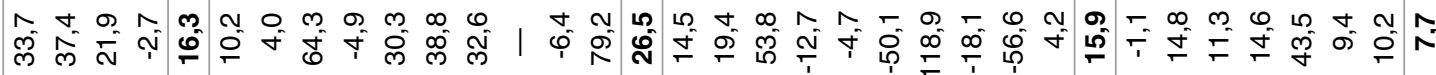

ఫ \& 灾

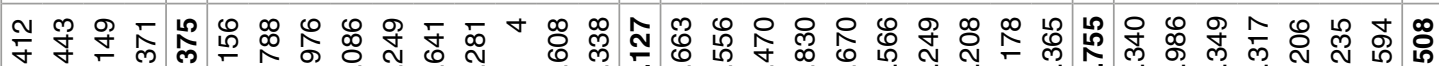

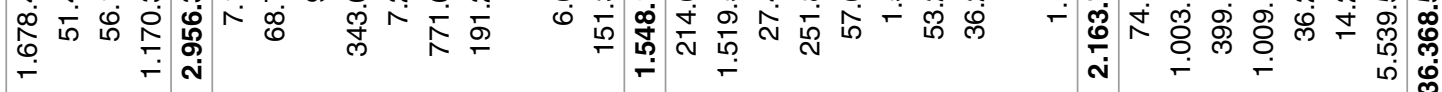

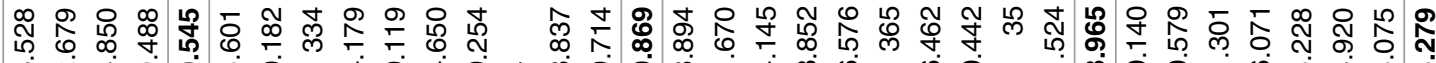
它

员 守

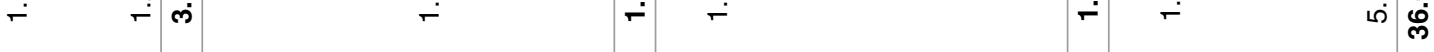

L

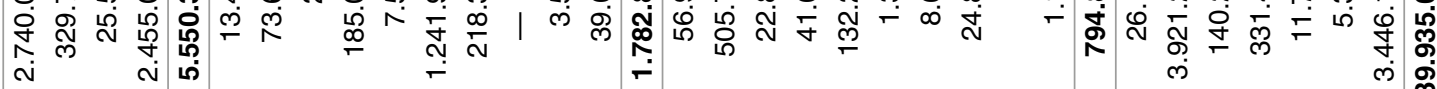
ర

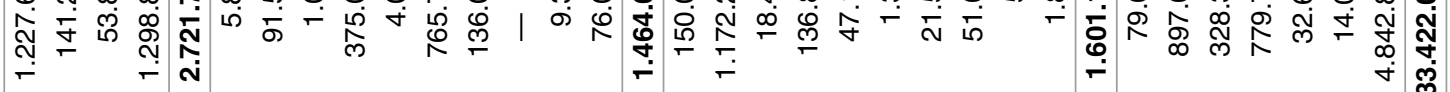

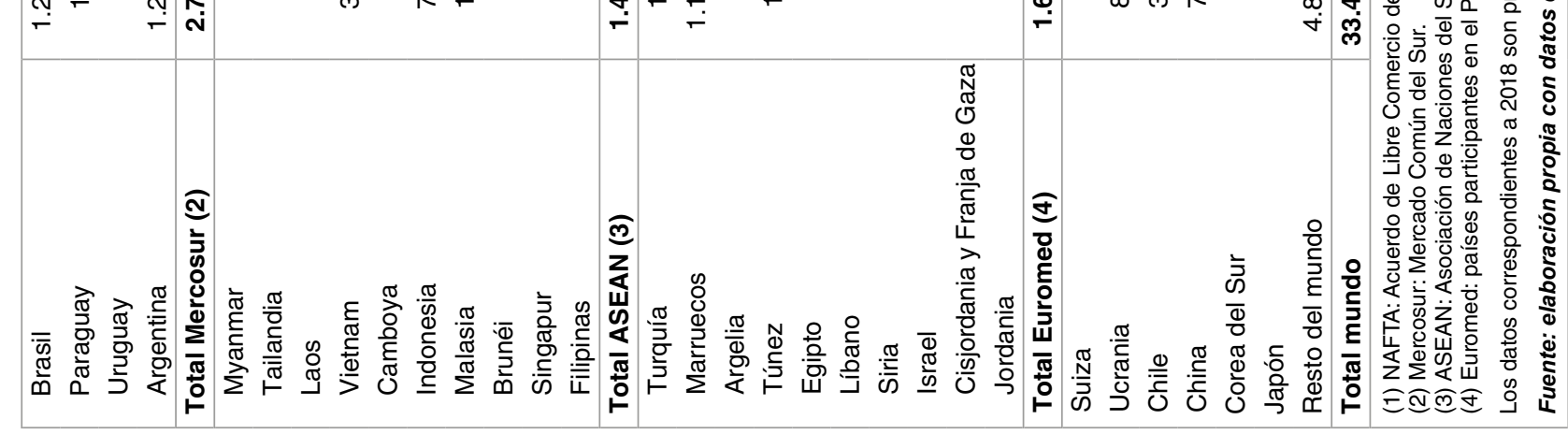


sanitarias detectadas en ciertos establecimientos cárnicos. Esto ha provocado que las importaciones procedentes de este país hayan descendido en un $20,5 \%$ con respecto a 2017 , pasando de 57,5 a 45,6 millones de euros.

- Desde el 22 de junio de 2018 se aplican derechos de importación adicionales a las importaciones en la UE de diversos productos originarios de EE UU, incluidos los agroalimentarios. Esto es consecuencia de la imposición estadounidense de derechos de importación adicionales a productos de acero y de aluminio.

- El 28 de septiembre de 2018 Sudáfrica finalmente aplicó medidas de salvaguardia para la carne de aves, aplicando derechos de importación del 35,3\% a carne de pollo del código del arancel sudafricano 0207.14.9. Estas medidas son aplicables desde el 28 de septiembre de 2018 hasta el 11 de marzo de 2019. Desde el 12 de marzo de 2019 hasta el 11 de marzo de 2020 se aplicará un arancel del $30 \%, 25 \%$ o $15 \%$ a los productos de carne de ave incluidos en el código 0207.14.9.

- El 1 de octubre de 2018 entró en vigor el Acuerdo entre la UE y Noruega sobre preferencias comerciales adicionales en el sector de los productos agrarios, que aumenta las preferencias ya existentes entre las partes del acuerdo, con base en lo dispuesto en el artículo 19 del Acuerdo sobre el Espacio Económico Europeo.

- El año 2018 ha sido el primero de aplicación completa del Acuerdo Económico y Comercial Global (CETA) entre la UE y Canadá, que incluye las concesiones comerciales recíprocas entre las partes del acuerdo. El balance de comercio entre las partes en el acuerdo ha sido positivo, con un aumento de las exportaciones de la UE a Canadá del $13 \%$ en valor y del $20 \%$ en volumen. Las importaciones de Canadá no han aumentado tanto, el 4,4\% en volumen, y el valor ha disminuido el $11 \%$ con respecto a 2017.

- El 1 de octubre de 2018 entró en vigor el Acuerdo con Nueva Zelanda en el ámbito del Acuerdo General sobre Aranceles Aduaneros y Comercio (GATT), como consecuencia de la ampliación de la UE a Croacia. Se amplían los contingentes arancelarios concedidos a este país para carne de bovino y ovino.

- En noviembre de 2018 España y China firmaron un protocolo sanitario de ampliación de los productos de porcino que España puede exportar a China, que incluye carne fresca, jamón curado con hueso y otros productos curados como lomo, salchichón y chorizo.

- En noviembre de 2018 España y China firmaron un protocolo sanitario de uva de mesa, que permite la exportación de esta fruta al mercado chino.

\section{Conclusión}

En 2018 se ha mantenido la tendencia, sostenida durante los últimos dieciocho años e intensificada desde la crisis económica, de saldos superavitarios de la balanza comercial agroalimentaria.

Esta evolución se ha producido en un contexto internacional caracterizado por tensiones en materia de política comercial y por renegociaciones y puesta en marcha de nuevos acuerdos comerciales que, en algunos casos, han tenido efectos directos en los flujos de comercio exterior de productos agroalimentarios. 